\title{
PENERAPAN MODEL WATERFALL DAN UML DALAM RANCANG BANGUN PROGRAM PEMBELIAN BARANGBERORIENTASI OBJEK PADA PT. FUJITA INDONESIA
}

\author{
${ }^{1)}$ Hardiyanto, ${ }^{\text {() }}$ Abdussomad, ${ }^{3)}$ Eko Haryadi, ${ }^{4)}$ Robi Sopandi, ${ }^{5)}$ Asep \\ Email 1)mashardiyanto962@gmail.com, ${ }^{2}$ abdussomad.bdu@nusamandiri.ac.id , \\ ${ }^{3)}$ ekoharyadi.5975@gmail.com , ${ }^{4)}$ robi.rbs@bsi.ac.id , ${ }^{5)}$ asep.aep@bsi.ac.id
}

\begin{abstract}
Abstrak
Berlakunya AEC (Asean Economic Comunity) di Indonesia, mengakibatkan perusahaan yang bergerak dalam industri jasa maupun industri lainnya harus mengikuti standar kerja dan operasional yang berlaku. Karena pada PT. Fujita Indonesia pengolahan data sistem pembelian barang masih manual, sehingga mengakibatkan kurangnya pelayanan dalam sistem pembelian barang yang diperlukan oleh masing-masing department pada PT. Fujita Indonesia. Dari permasalahan tersebut penulis mengajukan solusi untuk memperbaiki sistem pembelian barang menjadi terkomputerisasi. Sehingga masalah yang terjadi dapat teratasi dengan baik dan dapat meningkatkan mutu pembelian barang pada PT. Fujita Indonesia. Perancangan program pembelian barang ini meliputi pendataan barang, pendataan supplier, pembuatan form permintaan barang sampai kepada pembelian barang serta pembuatan laporan. Diharapkan dengan sistem ini dapat memperbaiki kekurangan yang sering terjadi.
\end{abstract}

Kata Kunci: Perancangan Program, Pembelian Barang, AEC (Asean Economic Comunity)

\begin{abstract}
The enactment of AEC (ASEAN Economic Comunity) in Indonesia, resulting in companies engaged in the service industry and other industries must follow the standards of work and operational applicable in the era. Because at PT. Fujita Indonesia data processing of goods purchasing system is still manual, resulting in lack of service in purchasing system of goods required by each department at PT. Fujita Indonesia. From these problems the authors propose solutions to improve the system of purchasing goods to be computerized. So that the problems that occur can be resolved properly and can improve the quality of goods purchases at PT. Fujita Indonesia. The design of this goods purchase program includes data collection, supplier data collection, making the request form of goods to the purchase of goods and making reports. It is hoped that with this system can improve the deficiencies that often occur.
\end{abstract}

Keyword: Program Design, Purchase of Goods, AEC (Asean Ecpnomic Community)

Jurnal Interkom Vol. 13 No. 4 - Januari 2019 


\section{Pendahuluan}

Seiring dengan berlakunya AEC (ASEAN Economic Community) atau sering kita sebut MEA (Masyarakat Ekonomi Asean) secara tidak langsung berpengaruh juga pada perkembangan teknologi informasi menjadi sebuah kebutuhan pokok dimasyarakat, terutama pada sistem informasi didunia industri yang ada di Indonesia harus dapat memberikan informasi yang dibutuhkan pada setiap tingkatan manajemen bagian harus akurat, tepat waktu, dan relevan. Penggunaan sistem informasi terkomputerisasi dan penggunaan perlengkapan pendukung yang memadai di perusahaan juga merupakan salah satu cara untuk mengantisipasi penyajian informasi agar lebih akurat, tepat waktu, dan relevan dalam mengambil sebuah keputusan dan sebagai pendukung sistem informasi yang akan digunakan

PT. Fujita Indonesia memiliki banyak kebutuhan barang dan material yang digunakan untuk mendukung operasional perlengkapan kantor sampai dengan kegiatan produksi yang dikendalikan oleh departemen purchasing, agar dapat memudahkan seluruh departemen dalam pengadaan barang yang dibutuhkan baik untuk keperluan operasional maupun produksi. Departemen purchasing memiliki fungsi untuk mengendalikan, menampung, membuat serta mengelola permintaan barang, pemesanan barang, pembelian barang sampai pendataan barang yang sudah dipesan oleh setiap departemen pada PT. Fujita Indonesia. Namun dalam penerapannya sampai saat ini, PT. Fujita Indonesia masih menggunakan sistem yang digunakan oleh kebanyakan perusahaan pada umumnya yaitu dengan dengan menggunakan Microsoft Excel dalam pengolahan data purchasing. dengan menggunakan sistem tersebut sering terjadi kesalahan-kesahan mulai dari ketidak cocokan data pemesanan barang antara bagian purchasing dengan bagian yang memesan barang tersebut.

\section{Tinjauan Pustaka}

Menurut Harumy (2016:4), menyatakan bahwa "Program adalah formulasi sebuah algoritma dalam bentuk bahasa pemrograman. Sehingga siap untuk dijalankan pada mesin komputer".

Menurut Kadir (2012:2) yang dimaksud "program adalah kumpulan intruksi yang digunakan untuk mengatur komputer agar melakukan suatu tindakan tertentu".

Jadi dapat disimpulkan bahwa program adalah sekumpulan intruksi atau perintah yang dibuat untuk mengatur dan memerintahkan komputer melakukan tindakan tertentu. Suatu program ditulis dengan bahasa pemrograman, bahasa pemrograman adalah bahasa buatan yang digunakan untuk mengendalikan perilaku dari sebuah mesin, biasanya berupa mesin komputer, sehingga dapat digunakan untuk memberitahu komputer tentang apa yang harus dilakukan.

\section{Bahasa Pemrograman Java}

Menurut Utomo (2013:2), menyatakan bahwa "Java merupakan bahasa pemrograman berorientasi objek yang sintaknya mengikuti bentuk bahasa $\mathrm{C}$ dan $\mathrm{C}++$ sehingga bagi para programmer bahasa $\mathrm{C}$ tidak akan kesulitan ketika akan bermigrasi ke bahasa Java karena sintaknya hampir sama".

\section{Pemrograman Berorientasi Objek}

Menurut Wardana (2010:24), mengatakan bahwa: "Pemrograman berorientasi object atau yang sering disebut Object Oriented Programming (OOP) adalah metode pemrograman, di mana developer membuat dan mengelompokkan kode-kode yang berkaitan menjadi suatu object. Sehingga setiap object dapat memiliki data dan fungsi sendiri, dan data serta fungsi tersebut dapat digunakan dengan memanggil object yang bersangkutan terlebih dahulu".

Adapun keuntungan menggunakan OOP dalam pembuatan aplikasi adalah:

1. Maintainability

2. Extensibility

3. Reusability

Konsep dasar pemrograman berorientasi objek yang harus dipahami Menurut Muslihudin dan Oktafianto (2016:56) adalah sebagai berikut:
1. Objek (Object) 
2. Kelas (Class)

3. Pembungkusan (Encapsulation)

4. Pewarisan (Inheritance) dan Generalisasi/ Spesialisasi

5. Polimorpisme (Polymorphism)

\section{Entity Relationship Diagram (ERD)}

Menurut

Fathansyah

(2012:81)

menyatakan bahwa: "Entity Relationship Diagram (ERD) merupakan komponenkomponen Himpunan Entitas dan Himpunan Relasi yang masing-masing dilengkapi dengan atribut-atribut yang merepresentasikan seluruh fakta dari 'dunia nyata' yang kita tinjau, dapat digambarkan dengan lebih sistematis dengan menggunakan Entity Relationship Diagram (ERD)".

\section{Unified Modeling Language (UML)}

Menurut Gata dan Grace Gata (2013:4), menyatakan bahwa "UnifiedModeling Language (UML) adalah bahasa spesifikasi standar yang dipergunakan untuk mendokumentasikan, menspesifikasikan dan membangun perangkat lunak". UML merupakan metodologi dalam mengembangkan sistem berorientasi objek dan juga merupakan alat untuk mendukung pengembangan sistem.

Sementara itu alat bantu yang digunakan untuk dalam perancangan berorientasi objek berbasiskan UML menurut Gata dan Grace Gata (2013:4) adalah sebagai berikut:

1. Use Case Diagram

2. Activity Diagram (Diagram Aktivitas)

3. Sequence Diagram (Diagram Urutan)

4. Class Diagram (Diagram Kelas)

\section{Pengujian Perangkat Lunak}

Menurut Pressman (2010:495), black-box testing juga disebut behavioral testing "merupakan pengujian yang berfokus pada persyaratan fungsional dari perangkat lunak. Artinya, teknik pengujian black-box memungkinkan untuk memperoleh kondisi input yang sepenuhnya akan melaksanakan semua persyaratan fungsional untuk suatu program".

\section{Metode Penelitian}

Menurut Sukamto dan Shalahuddin (2014:28), "model waterfall adalah model SDLC (Sofware Development Life Cycle) yang paling sederhana. Model ini hanya cocok untuk pengembangan perangkat lunak dengan spesifikasi yang tidak berubah-ubah". Model SDLC air terjun (waterfall) sering juga disebut dengan model sekuensial linier (squential linear) atau alur hidup klasik (classic life cycle). Model air terjun menyediakan pendekatan alur hidup perangkat lunak secara sekuensian atau terurut dimulai dari analisis, desain, pengkodean, pengujian dan tahap pendukung (support). Berikut adalah model air terjun (waterfall):

1. Analisis Kebutuhan Perangkat Lunak

Proses pengumpulan kebutuhan dilakukan secara intensif untuk menspesifikasikan kebutuhan perangkat lunak agar dapat dipahami perangkat lunak seperti apa yang dibutuhkan oleh user. Spesifikasi kebutuhan perangkat lunak pada tahap ini perlu untuk didokumentasikan.

2. Desain

Desain perangkat lunak adalah proses multi langkah yang fokus pada desain pembuatan program perangkat lunak termasuk struktur data, arsitektur perangkat lunak, representasi antar muka, dan prosedur pengkodean. Tahap ini mentranslasi kebutuhan perangkat lunak dari tahap analisis kebutuhan ke representasi desain agar dapat di implementasikan menjadi program pada tahap selanjutnya. Desain perangkat lunak yang dihasilkan pada tahap ini juga perlu di dokumentasikan.

3. Pembuatan Kode Program

Desain harus ditranslasikan ke dalam program perangkat lunak. Hasi dari tahap ini adalah program komputer sesuai dengan desain yang telah dibuat pada tahap desain.

4. Pengujian

Pengujian fokus pada perangkat lunak secara dari segi lojik dan fungsional dan memastikan bahwa semua bagian sudah diuji. Hal ini dilakukan untuk meminimalisir kesalahan (error) dan memastikan keluaran 
yang dihasilkan sesuai dengan yang di inginkan.

5. Pendukung (support) atau pemeliharaan (maintenance)

Tidak menuntut kemungkinan sebuah perangkat lunak mengalami perubahan ketika sudah dikirimkan ke user. Perubahan bisa terjadi karena adanya kesalahan yang muncul dan tidak terdeteksi saat pengujian atau perangkat lunak harus beradaptasi dengan lingkungan baru. Tahap pendukung atau pemeliharaan dapat mengulangi proses pengembangan mulai dari analisis spesifikasi untuk perubahan perangkat lunak yang sudah ada, tapi tidak untuk membuat perangkat lunak baru.

\section{Hasil Dan Pembahasan}

A. Kebutuhan Pengguna

Aplikasi pembelian barang terdapat 3 (tiga) pengguna yang dapat saling berinteraksi dalam lingkungan system, yaitu: staff departemen, staff purchasing, dan staff IT. Ketiga pengguna tersebut memiliki karakteristik interaksi dengan system yang berbeda-beda dan memiliki kebutuhan informasi yang berbeda-beda, seperti berikut:

A.1. Skenario Kebutuhan Staff IT
1) Mengelola data barang
2) Mengelola data user
3) Mengelola data supllier
4) Mengelola data departemen
5) Menginput formulir request barang
6) Menginput purchase order
7) Membuat laporan

A.2. Skenario Kebutuhan Staff Departement

1) Melihat informasi data barang

2) Membuat form request barang baru

A.3. Skenario Kebutuhan Staff Departement Purchasing

1) Mengelola data barang

2) Mengecek informasi stok barang

3) Mengelola data supplier

4) Mengecek informasi data supplier

5) Membuat purchase order

6) Membuat laporan purchase order

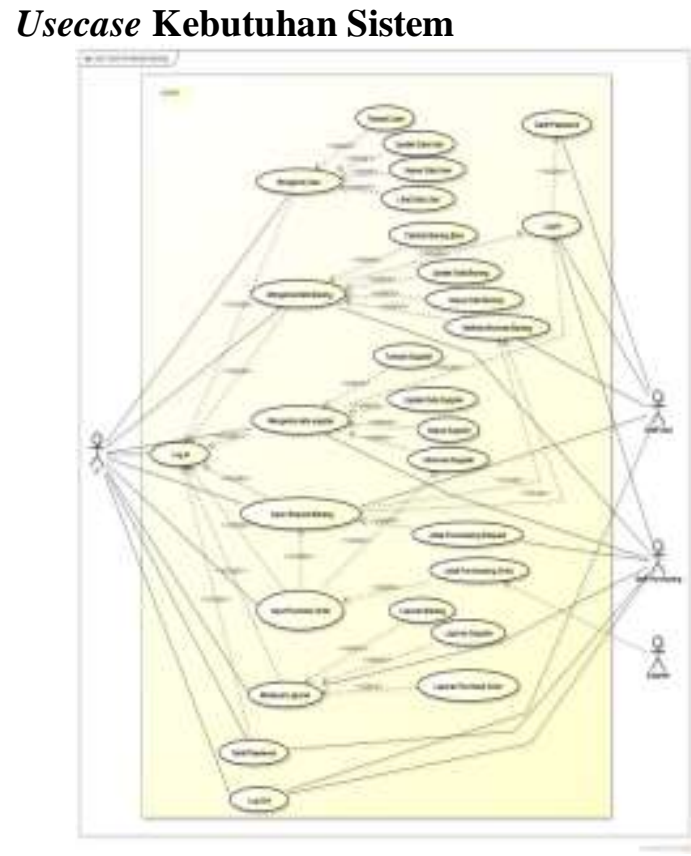

Gambar 1. Use Case Diagram

\section{Rancangan Basis Data}

1. Rancangan Entity RelationshipDiagram

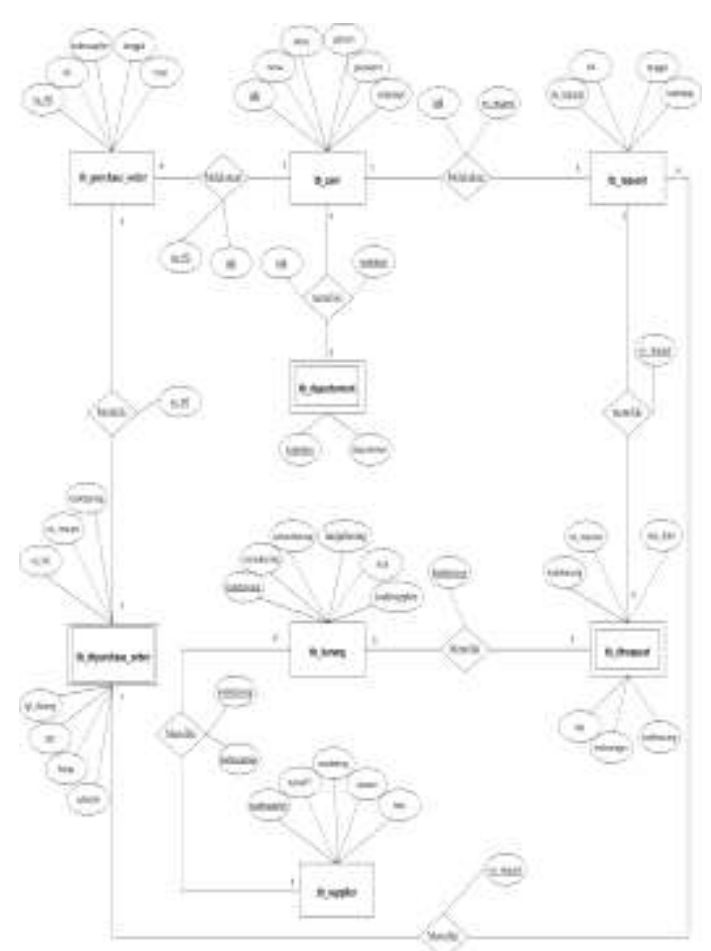

Gambar 2. Entity Relationship Diagram 
2. Rancangan Logical Record Structure

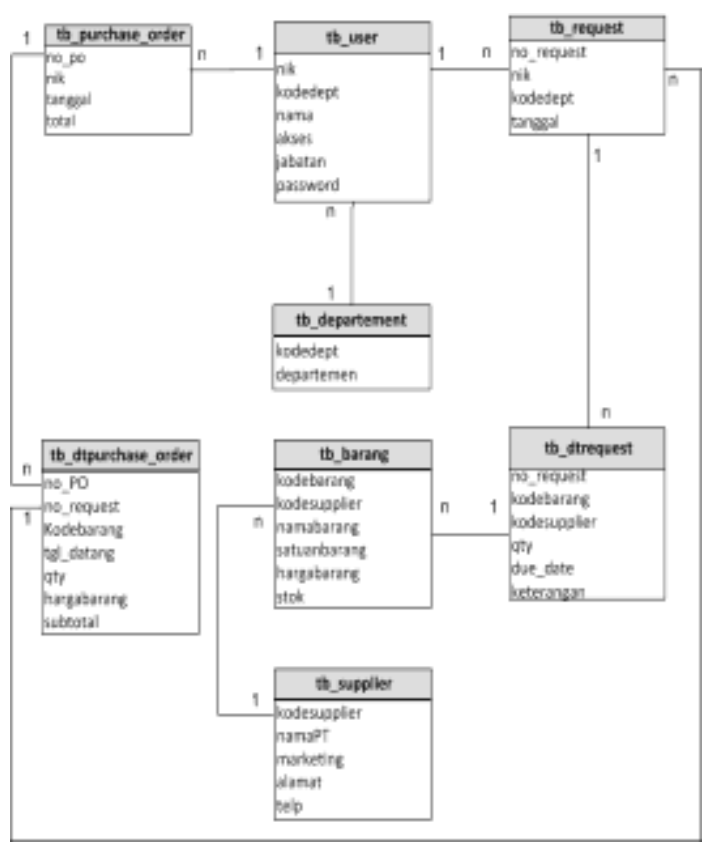

Gambar 3. Logical Record Structure

3. Rancangan Arsitektur Perangkat Lunak A. Class Diagram

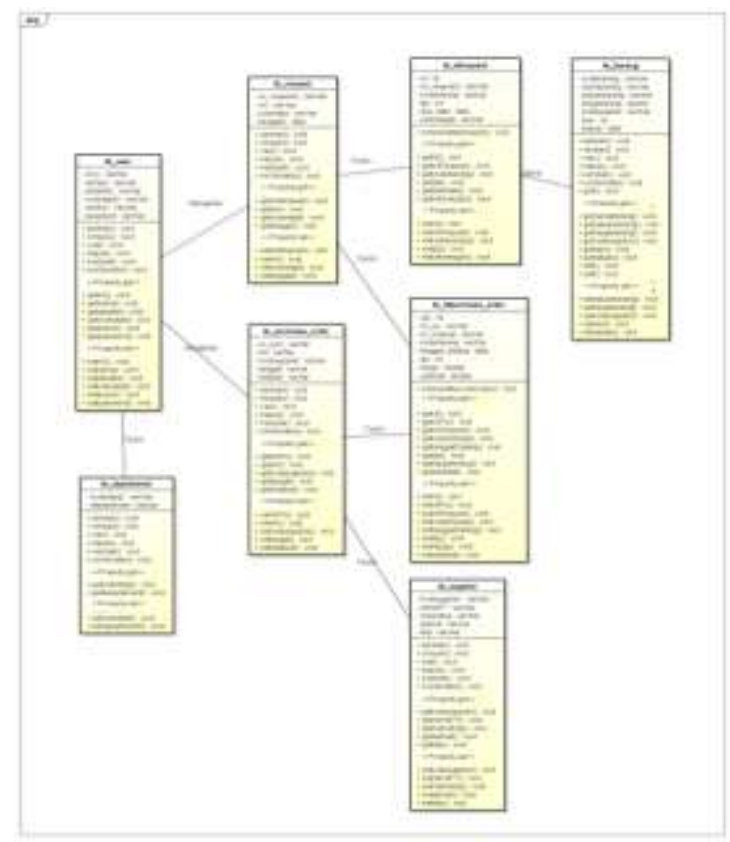

Gambar 4. Class Diagram
B. Sequence Diagram

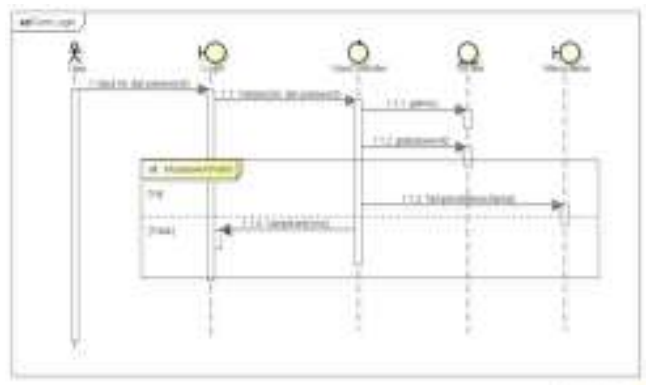

Gambar 5. Sequence Diagram Login

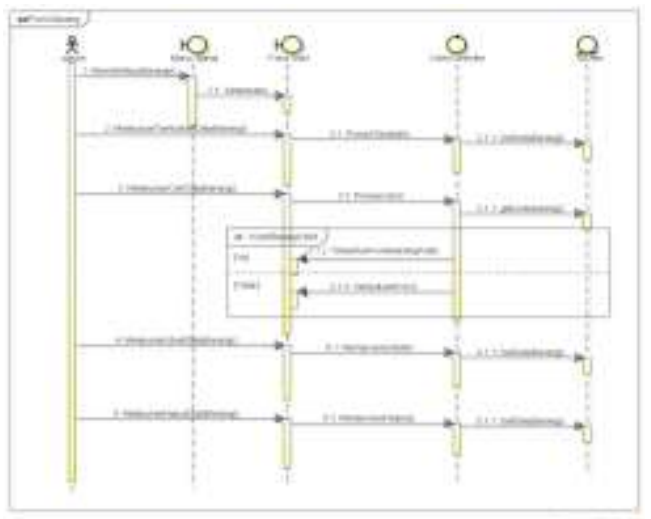

Gambar 6. Sequence Diagram Data Barang

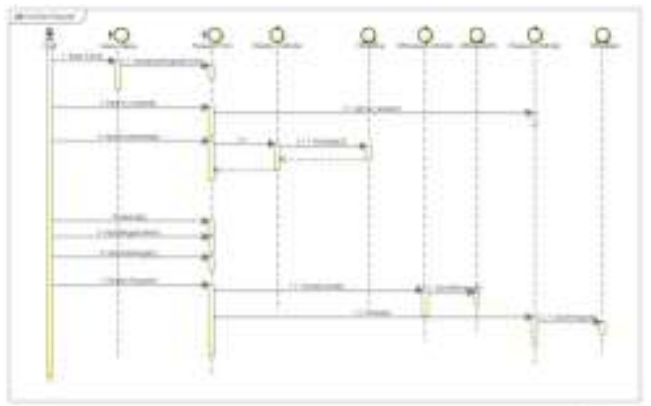

Gambar 7 Sequence Diagram Data Request Barang

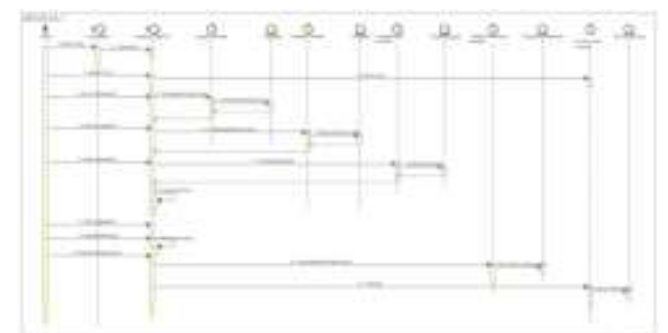

Gambar 8 Sequence Diagram data Purchase Order 


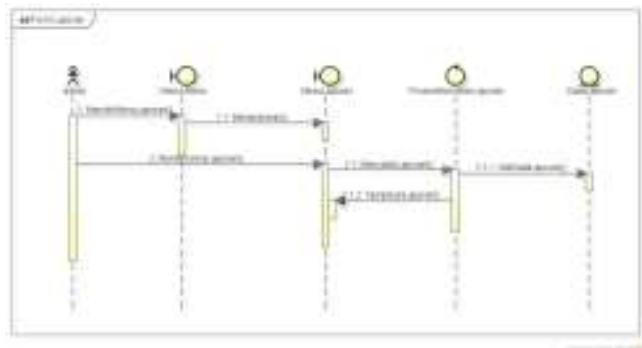

Gambar 9. Sequence Diagram Laporan

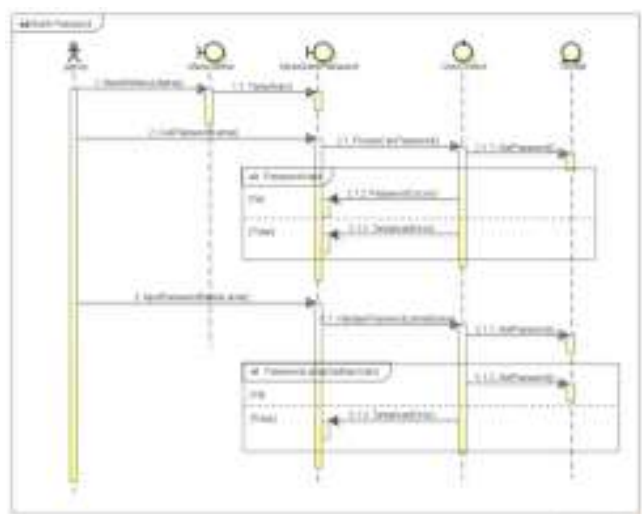

Gambar 10 Sequence Diagram Ganti Password

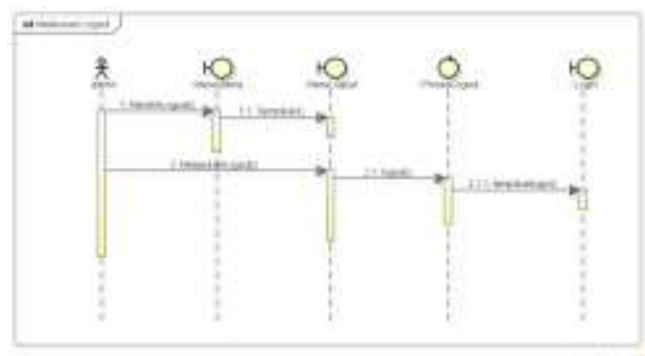

Gambar 11 Sequence Diagram Logout

\section{Implementasi Rancangan Antar Muka}

1. Halaman Login

Halaman login digunakan untuk masuk dan mengakses aplikasi.

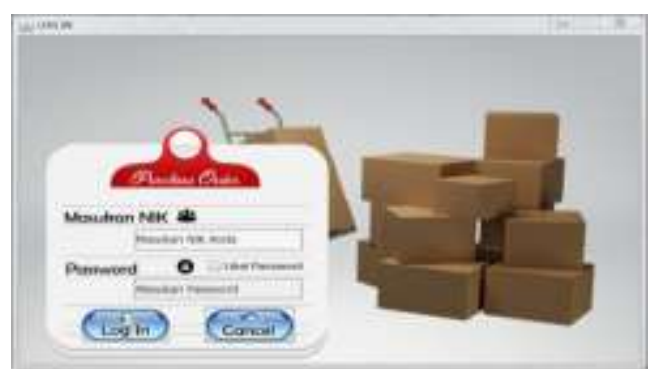

Gambar 12. Halaman Login
2. Halaman Menu Utama

Pengguna dapat melihat fitur-fitur pada aplikasi dan dapat menggunakannya sesuai kebutuhan.

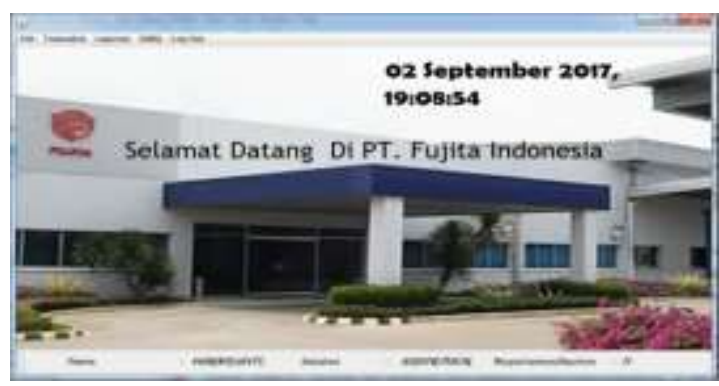

Gambar 13. Halaman Menu Utama

3. Halaman Data Barang

Pengguna dapat menambahkan data barang baru didalam halaman data barang.

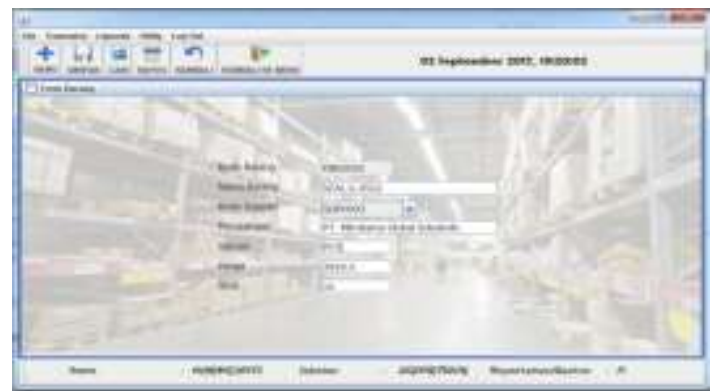

Gambar 14. Halaman Data Barang

4. Halaman Data Request Barang

Pengguna dapat mengelola purchase request dan dapat melihat hasilnya pada halaman ini.

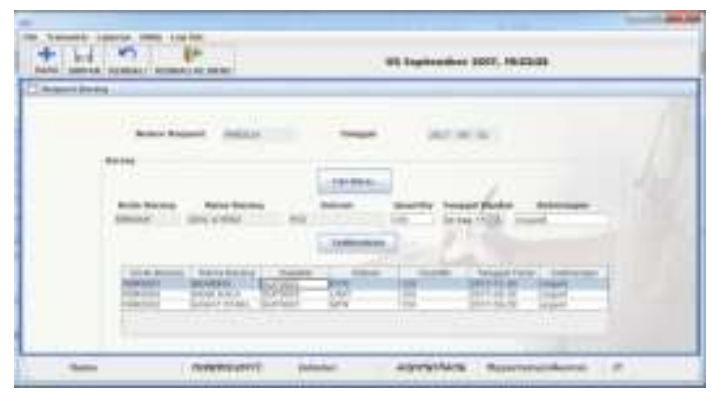

Gambar 15. Halaman Data Purchase Request

5. Halaman Data Purchase Order

Pengguna dapat mengelola purchase order dan dapat melihat hasilnya pada halaman ini. 


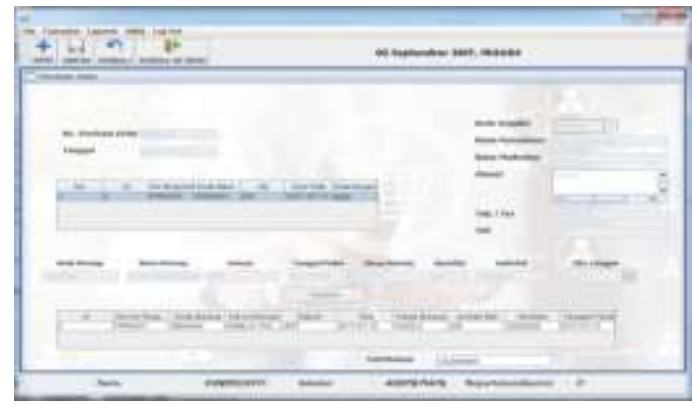

Gambar 16. Halaman Data Purchase Order

6. Halaman Laporan

Pengguna dapat melihat laporan purchase request dan purchase order, setelah menginputkan bulan dan tahun pembuatan transaksi.

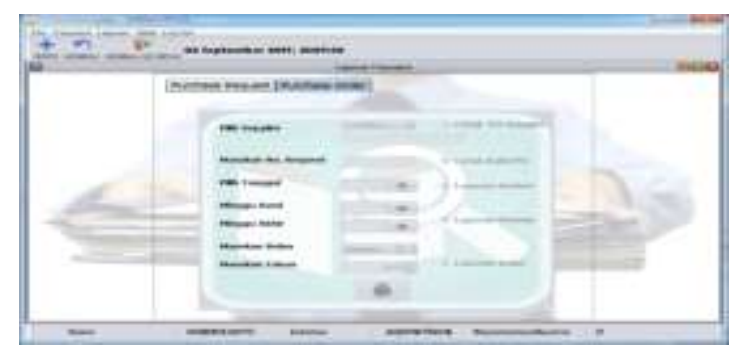

Gambar 17. Halaman Halaman Laporan

\section{Kesimpulan dan Saran}

\section{Kesimpulan}

Sistem pembelian barang yang telah terkomputerisasi memiliki banyak manfaat yang di peroleh dalam proses transaksi pembelian barang yaitu :

1. Database yang berisi data harga barang dan stok barang serta data supplier sudah tersedia, sehingga pengolahan data bisa lebih terorganisir dan terkontrol.

2. Aplikasi sistem administrasi pembelian barang sudah berjalan dengan baik karena sudah adanya pencatatan dan pengarsipan laporan, administrasi pembelian barang sudah cukup memberikan informasi yang lebih baik dan cepat.

3. Perhitungan mengenai pembelian barang dapat dilakukan lebih cepat, tepat dan akurat, Dengan adanya basis data dengan komputer mepermudah pencariaan atau pengecekan stok barang yang ada digudang.
4. Pengambilan keputusan yang lebih cepat, tepat, akurat, terpercaya, terutama bagi Pimpinan dalam pengambilan keputusan. Mengurangi kesimpangsiuran sehingga aktivitas akan lebih pasti dan menghasilkan laporan-laporan proses pembelian barang yang berkualitas serta menyeluruh. Hal tersebut dapat di wujudkan karena setiap proses pembuatan laporan dieksekusi secara otomatis oleh mesin komputer.

Dengan adanya aplikasi pembelian barang ini maka setiap aktivitas di dalam bisnis dapat terus menerus dipantau.

\section{Saran}

Komputer tidak akan bekerja secara maksimal apabila pemakai tidak menggunakannya dengan baik. Untuk itu agar dapat hasil yang maksimal karyawan PT. Fujita Indonesia harus memiliki pengetahuan tentang pengunaan dan pengoperasian komputer dengan baik untuk menghindari kerusakan media penyimpanan data.

\section{Daftar Pustaka}

Fathansyah. 2012. Basis Data. Bandung:Informatika Bandung.

Gata, Windu dan Grace Gata. 2013. Sukses Membangun Aplikasi Penjualan dengan Java. Jakarta: PT. Elex Media Komputindo

Harumy, T. Henny Febriana, Agus Perdana.W dan Indri Sulistianingsinh. 2016. Belajar Dasar Algoritma dan Pemrograman $C++$.Yogyakarta: Deepublish.

Kadir, Abdul. 2012. Algoritma \& Pemrograman Menggunakan Java. Yogyakarta: Andi Offset.

Muslihudin, Muhamad dan Oktafianto. 2016. Analisis dan Perancangan Sistem Informasi Menggunakan Model Terstruktur dan UML. Yogyakarta: CV.Andi Offset.

Pressman, Roger S. 2010. Software engineering : a practitioner's approach. New York: Mc Graw Hill. 
Sukamto, Rosa A, M. Salahuddin. 2014. Rekayasa Perangkat Lunak Terstruktur dan Berorientasi Objek. Bandung: Informatika Bandung.

Utomo Eko Priyo.2013. Cara Cepat dan Mudah Belajar Java SE7. Yogyakarta: Andi Offset.

Wardana. 2010. Menjadi Master dengan FrameworkCodelgniter. Jakarta:PT. Elex Media Komputindo. 